TRANSFORMTIKA, Vol.16, No.2, January 2018, pp. 126 - 134

ISSN: 1693-3656,

journals.usm.ac.id/index.php/transformatika

page 126

\title{
Improvement of Microtic Based Wireless LAN Performance in SMKN 2 Semarang
}

\author{
Sri Handayani ${ }^{1}$, Agus Priyanto ${ }^{2}$ \\ ${ }^{1}$ Program Studi Teknik Informatika, Universitas Semarang \\ Jl. Soekarno Hatta Semarang, (024) 6702757, e-mail: sri@usm.ac.id \\ ${ }^{2}$ Program Studi Teknik Informatika, Universitas Semarang \\ Jl. Soekarno Hatta Semarang, (024) 6702757, e-mail: aguspriyantto7@gmail.com
}

\section{ARTICLE INFO}

Article history:

Received 22 January 2019

Received in revised form 25 January 2019

Accepted 25 January 2019

Available online 30 January 2019

\begin{abstract}
ABSTRAK
Pemanfaatan koneksi internet di SMKN 2 Semarang saat ini merupakan hal yang sangat penting sebagai sarana untuk menunjang proses belajar mengajar juga koneksi internet yang stabil dibutuhkan saat berlangsungnya UNBK (Ujian Nasional Berbasis Komputer). Kondisi koneksi internet yang putus sambung dalam kegiatan ujian harus dihindari agar para siswa dapat fokus mengerjakan soal ujian berbasis komputer. Seiring bertambahnya peserta didik dan sarana laboratorium di SMKN 2 Semarang, maka dibutuhkan pengelolaan koneksi internet berupa wireless LAN yang digunakan oleh SMKN 2 Semarang. Pengelolaan wireless LAN berbasis mikrotik di SMKN 2 Semarang bertujuan untuk meningkatkan performa dari layanan internet dari modem Indihome dan modem Astinet dapat saling menunjang kestabilan koneksi internet, terutama saat berlangsungnya ujian tengah dan ujian akhir yang telah berbasis komputer dan UNBK.

Keywords: Performa, Wireless, SMKN 2 Semarang
\end{abstract}

\section{Pendahuluan}

\subsection{Latar Belakang}

SMK Negeri 2 Semarang merupakan sekolah negeri unggulan di kota Semarang. Terletak di jalan Dr.Cipto 121 A Semarang berdiri pada tanggal 26 Juni 1951. SMK Negeri 2 Semarang dahulu SMEA 1 Semarang berdiri pada tanggal 26 Juni 1951, berdasarkan SK Menteri Pendidikan dan Kebudayaan No. 2881 / BIII / 51 dengan nama SMEA Negeri Semarang.

Berdasarkan Surat Edaran Sekjen Depdikbud nomor : 41007/A.45/OT/1997 tertanggal 3 April 1997 perihal tindak lanjut Keptutusan Menteri Pendidikan dan Kebudayaan Nomor : 034.035 dan 036 / O / 1997 tentang Perubahan Nomenklatur SMP menjadi SLTP, SMA menjadi SMU dan SMKTA menjadi SMK, maka SMEA 1 Semarang namanya berubah menjadi SMK Negeri 2 Semarang. Dalam perjalanan waktu, sekolah ini terus berkembang sebagai Lembaga Pendidikan berbasis Bisnis Manajemen yang memiliki 5 Kompetensi Keahlian yaitu Rekayasa Perangkat Lunak, Usaha Perjalanan Wisata, Akuntansi dan Keuangan Lembaga, Otomatisasi dan Tata Kelola Perkantoran, dan Bisnis Daring dan Pemasaran. SMK Negeri 2 Semarang juga sebagai sekolah Adiwiyata Mandiri sejak tahun 2013.

Received January 22, 2019; Revised January 25, 2019; Accepted January 25, 2019. 
SMKN 2 Semarang telah menjadi sekolah Adiwiyata Mandiri dengan lingkungan sekolah yang nyaman, ditunjang gedung pembelajaran, laboratorium praktek komputer,maka internet sudah menjadi kebutuhan pokok untuk sarana pembelajaran bagi para siswa dan saran untuk pekerjaan bagi guru dan karyawan. Sekarang ini SMK Negeri 2 Semarang memiliki 2 modem internet yaitu modem Indihome dengan kapasitas bandwidth $100 \mathrm{Mbps}$, modem Astinet dengan kapasitas bandwidth 20 Mbps. Tugas penting bagi administrator jaringan untuk melakukan pengelolaan internet agar dapat diakses dengan lancar tanpa kendala selama 24 jam. Tetap aktifnya koneksi internet selama 24 jam suatu saat akan mengurangi performa perangkat jaringan di SMKN 2 Semarang.

\section{Metode Penelitian}

\subsection{Metode Pengumpulan Data}

Dalam mengumpulkan data, penulis menggunakan teknik pengumpulan data sebagai berikut:

1. Wawancara

Metode wawancara adalah mencari informasi secara langsung dengan cara bertanya jawab kepada Zakaria Adiwibowo selaku admin jaringan di SMKN 2 Semarang.

2. Observasi

Pada tahap ini penulis melakukan pengujian secara langsung dilapangan dengan menggunakan akses internet wifi di SMK Negeri 2 Semarang.

3. Studi Pustaka

Pada tahap ini penulis melakukan pengumpulann data menggunakan sumber yang dapat diperoleh dari internet, literatur, buku, dokumen yang ada di perpustakaan yang ada hubungannya dengan objek penelitian.

\subsection{Jenis Data}

Dari metode pengumpulan data tersebut didapatkan data yang diklasifikasikan sebagai berikut

1. Data Primer

Data Primer adalah data yang diperoleh melalui wawancara dan observasi tentang jaringan wireless yang ada di SMK Negeri 2 Semarang.

2. Data Sekunder

Data Sekunder adalah data yang diperoleh dari buku - buku dengan topik mengenai jaringan komputer, mikrotik, manual book dari vendor jaringan dan literatur lain yang mendukung laporan.

\subsection{Metode Pengembangan Sistem}

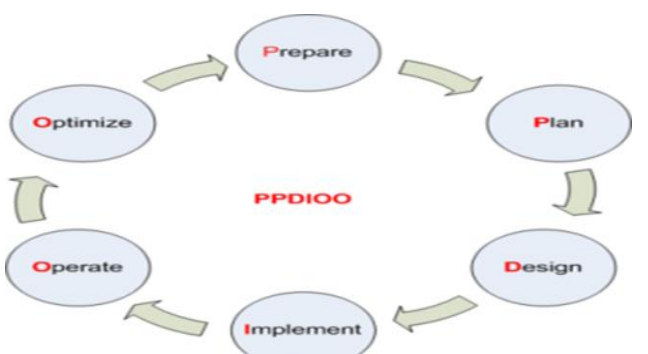

Gambar 1. Metode PPDIOO (CCD 640-864 Official Cert Guide)

A. $\quad$ Prepare

Dalam model pengembangan sistem PPDIOO fase pertama dimulai dari fase prepare atau melakukan analisa terhadap masalah yang ada yaitu bagaimana meningkatkan performa wireless LAN yang dapat memberikan kemudahan, kelancaran, keamanan dan kestabilitan jaringan internet yaitu dengan dibuatnya penjadwalan dan tahapan pelaksanaan sehingga dapat terkontrol dan berjalan dengan baik sesuai rencana awal. 


\section{B. Planning}

Untuk tahap selanjutnya adalah tahap plan, yaitu merencanakan apa yang sudah dipersiapkan dari sebelumnya dengan mempersiapkan peralatan kebutuhan yang dapat mendukung sehingga dapat memberikan kemudahan dan kelancaran untuk membangun sebuah hotspot baik secara software maupun hardware.

C. Design

Dalam tahapan design ini membuat denah lokasi titik-titik yang membutuhkan hotspot di lingkungan sekolah yang dimana pengguna dapat akses dengan mudah dan merancang topologi jaringan dengan aplikasi cisco paket tracer agar jaringan terkontrol dengan baik dan lancar disertai dengan konfigurasi yang dilakukan pada masing-masing perangkat, dimana terdapat satu unit mikrotik, dua modem internet, dan empat unit acces point di lingkungan sekolah.

D. Implement

Dalam tahap ini menerapkan semua yang telah direncanakan, mencangkup instalasi serta konfigurasi terhadap rancangan topologi, dan konfigurasi yang dilakukan pada masingmasing perangkat, baik pada perangkat mikrotik maupun pada acces point, seperti konfigurasi hotspot pada router mikrotik, load balancing dengan metode ECMP (Equal Cost Multi Path), reboot otomatis dengan memberikan perintah atau script pada menu scheduler, dan yang terakhir konfigurasi waktu akses internet pada firewall filter rules.

E. Operate

Dalam tahap ini diperlukan adanya pengujian terhadap jaringan wireless agar berjalan sesuai dengan analisis awal yaitu yang pertama memudahkan dan melancarkan mengakses hotspot dengan akun login username password dan bandwith yang sudah ditentukan, kedua melakukan pengujian metode load balancing dengan cara memutuskan salah satu koneksi modem internet apakah modem yang lain dapat membackup koneksi, ketiga menguji apakah router dapat melakukan reboot secara otomatis yang sudah tersistem dengan perintah script pada menu scheduler dan yang terakhir menguji koneksi hotspot pada saat diluar jam kerja apakah dalam keadaan offline.

F. Optimize

Tahap ini memerlukan perhatian khusus yang perlu dibuat untuk melakukan perawatan dan pemeliharaan pada jaringan baik secara software maupun hardware, jika sistem yang telah di rancang dan dibangun sudah berjalan cukup lama dan terjadi troubleshoot yang cukup berat maka kembali pada awal fase PPDIOO. Untuk memudahkan dalam perawatan dan pemeliharaan maka dibuat berupa penjadwalan yang dimana dapat dilakukan perawatan dan pemeliharaan pada saat diluar hari kerja, sehingga tidak mengganggu pengguna internet.

\section{Hasil dan Analisis}

\subsection{Prepare}

Pada pelaksanaan penelitian ini yang bertempat di SMK Negeri 2 Semarang dimulai pada bulan Oktober 2018 sampai bulan November 2018 yang dimana sudah ditentukan kegiatan per minggu agar pelaksanaan penelitian ini berjalan dengan lancar dan terarah. 
Kemudian melakukan identifikasi di lapangan serta mengamati permasalahan yang timbul yaitu bagaimana memberikan kemudahan, kelancaran dan keamanan dalam mengakses internet hotspot yang akan digunakan oleh Civitas Akademika di area hostspot taman SMK Negeri 2 Semarang.

Berdasarkan hasil survey, internet hotspot di taman SMK Negeri 2 Semarang belum memberikan kemudahan, kelancaran, dan keamanan, kemudian layanan akses internet hotspot aktif selama 24 jam dalam seminggu sehingga pada saat hari libur dan diluar jam kerja internet akan selalu aktif dan semakin lama mesin perangkat itu aktif maka semakin turun performa dari mesin router salah satunya adalah CPU load akan mencapai $100 \%$ tentu akan terasa berat selain itu juga pengguna hotspot diluar lingkungan sekolah dapat mengakses diluar jam kerja maka diperlukan sebuah keamanan pada jaringan.

\subsection{Planing}

Tahap selanjutnya adalah plan, yaitu merencanakan kebutuhan yang dibutuhkan untuk memberikan kemudahan, kelancaran dan keamanan internet hotspot di taman SMK negeri 2 Semarang. Adapun alat dan bahan yang dibutuhkan yaitu :

\section{Satu Unit Laptop}

\section{Acces Point}

Acces point berfungsi sebagai media jaringan hotspot. Perangkat yang digunakan adalah acces point TP-Link EAP110.

\section{Router mikrotik RB750}

Router ini memiliki banyak fitur yang harus dikonfigurasi mulai dari membuat server hotspot, managemen hotspot, serta memberikan keamanan hotspot.

\section{Kabel UTP}

Kabel UTP digunakan untuk penghubung jaringan untuk koneksi internet. Menggunakan kabel Belden original agar penggunakan bisa dalam jangka panjang untuk mengurangi permasalahan koneksi kabel.

\section{Winbox}

Winbox adalah aplikasi untuk meremot mikrotik yang di rilis oleh mikrotik sendiri. Berfungsi untuk mempermudah dalam konfigurasi router dengan sistem operasi windows.

\section{Mozila Firefox}

Aplikasi mozila firefox berfungsi untuk melakukan percobaan akses internet hotspot serta menampilkan request acces internet di halaman login hotspot.

7.Aplikasi Android SpeedTest

Aplikasi speedtest berfungsi untuk menguji kecepatan atau bandwidth internet hotspot yang didapatkan pada akun user masing-masing aplikasi ini terinstal di android. Tampilan SpeedTest Bandwidth seperti terlihat pada Gambar 3.1

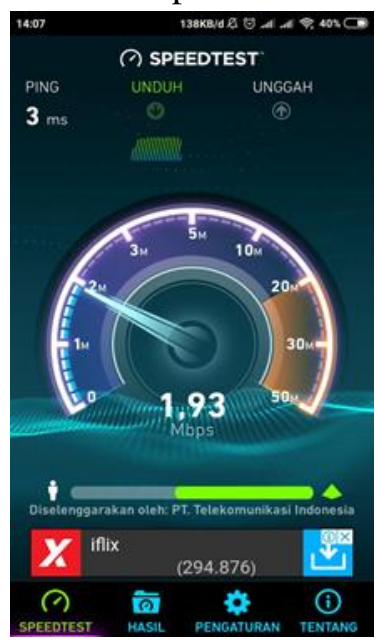

Gambar 3.1. Tampilan Speed Test 


\subsection{Design}

Tahapan design ini dibuat suatu topologi jaringan dengan jumlah empat unit acces point yang terpasang di area taman SMK Negeri 2 Semarang secara langsung terhubung dengan router dan modem di ruang teknisi. Rancangan lokasi internet hotspot seperti terlihat pada Gambar 3.2 sedangkan untuk rancangan topologi jaringan internet hotspot terlihat pada Gambar 3.3

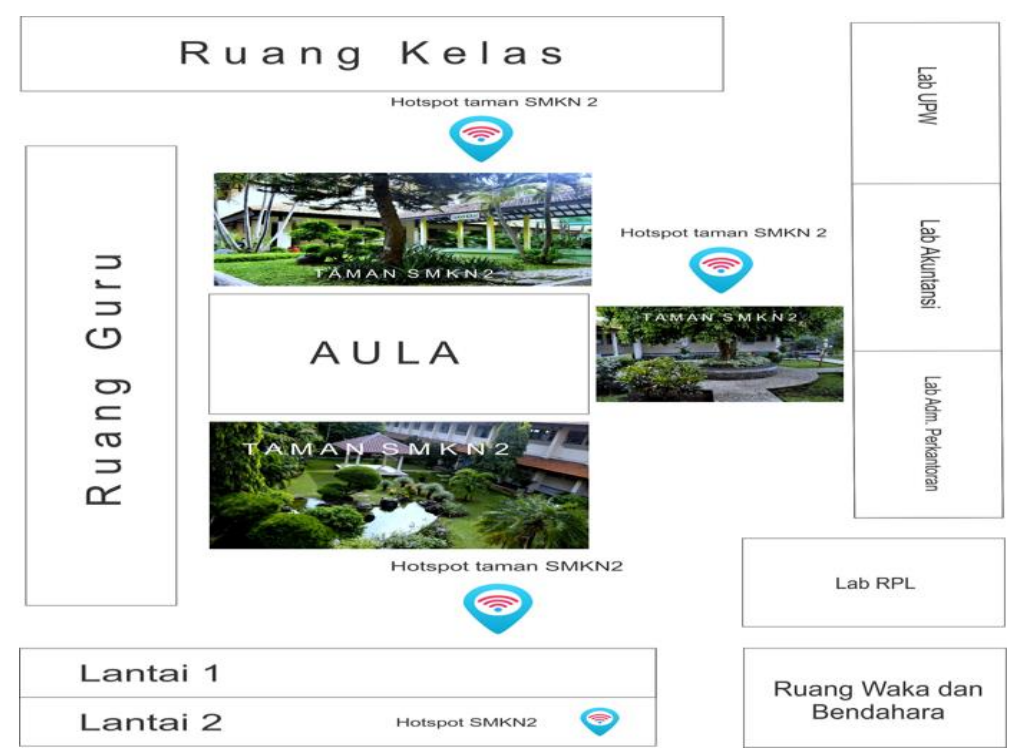

Gambar 3.2 Rancangan Lokasi Hootspot

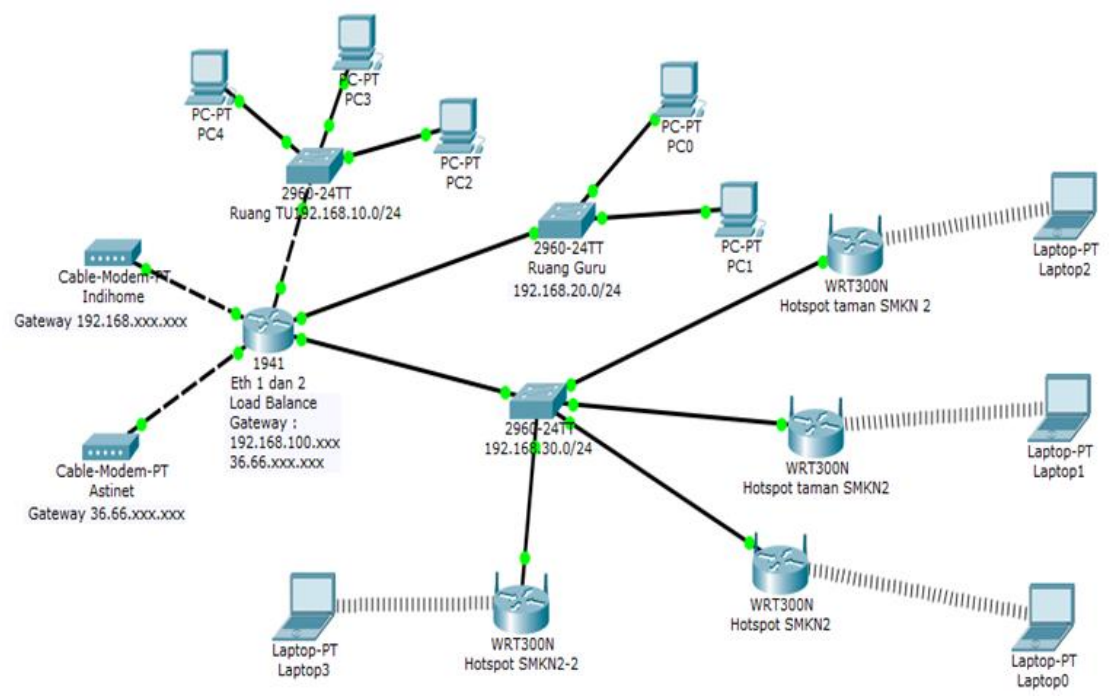

Gambar 3.3. Rancangan Topologi Lokasi Hotspot

TRANSFORMTIKA, Vol.16, No.2, January 2018, pp. 126 - 134 


\subsection{Implementasi}

1. Melakukan Konfigurasi Hotspot

a. Interfaces

Interfaces dengan masuk ke menu sebelah kiri kemudian pilih interfaces, maka akan tampil sebanyak lima ether pada ether-1 digunakan untuk interfaces modem ISP-1, ether-2 digunakan untuk interfaces modem ISP-2, ether-3 digunakan untuk interfaces yang menuju ke jaringan ruang TU, ether-4 digunakan untuk interfaces yang menuju ke jaringan ruang Guru sedangkan untuk ether-5 yang digunakan sebagai hotspot. Tampilan interfaces list ether terlihat pada gambar 3.4.

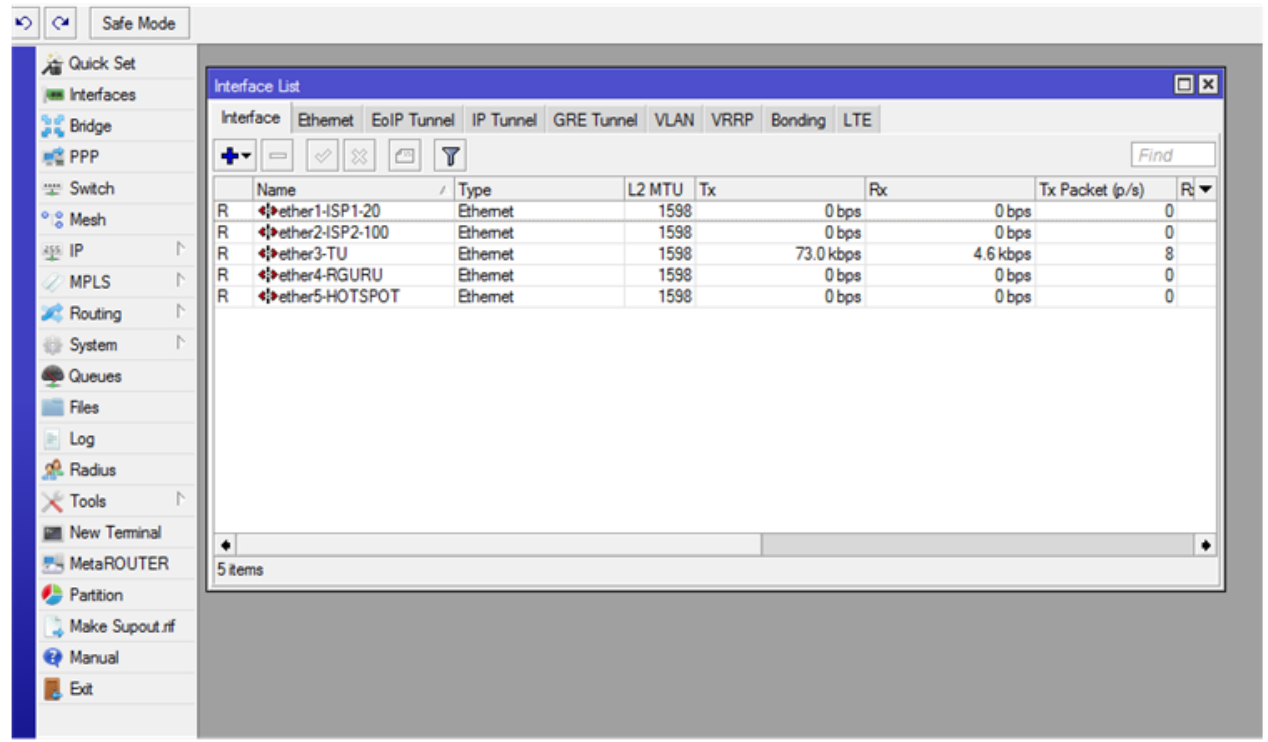

Gambar 3.4. Tampilan interface list ether

b. IP Address

Penerapan IP Address pada tiap interfaces, pada ether-1 digunakan untuk ISP 1, ether-2 digunakan untuk ISP 2, dan ether-5 digunakan untuk interfaces hotspot yang mana sudah terkonfigurasi IP Address masing-masing berbeda. Tampilan Address List terlihat pada Gambar 3.5.

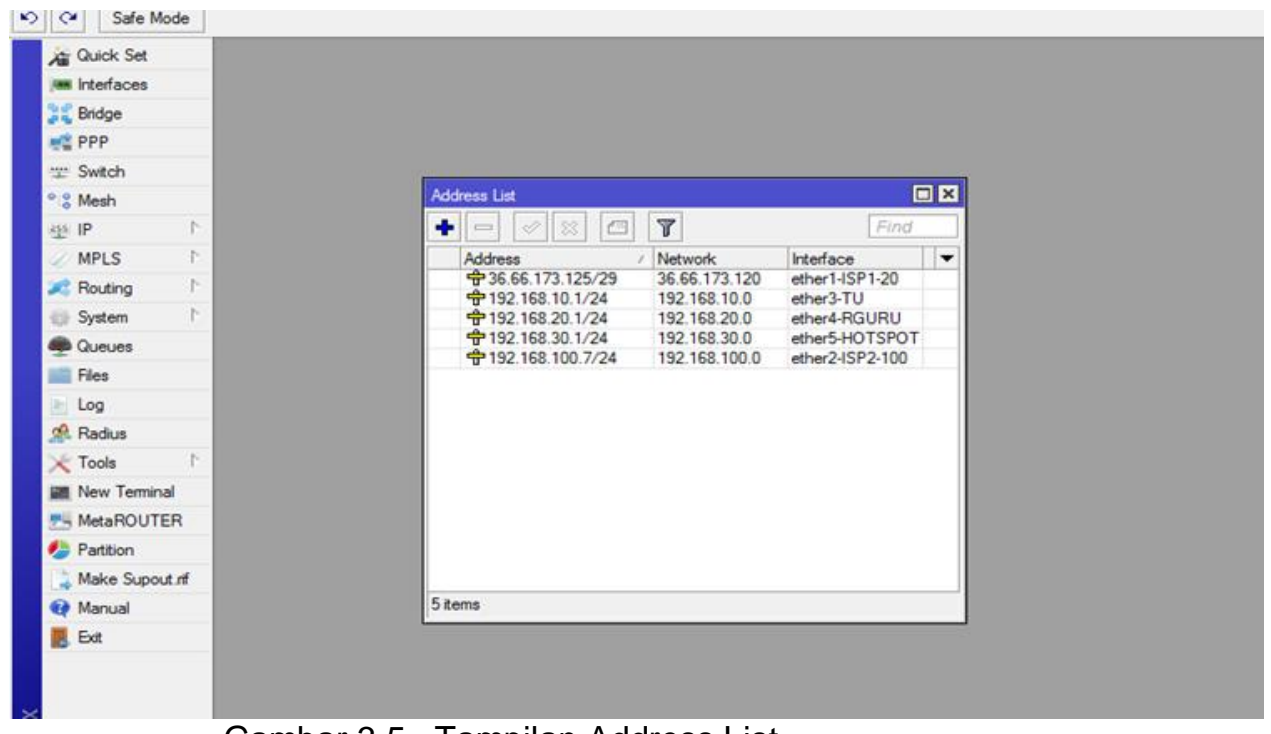

Gambar 3.5. Tampilan Address List 
c. Konfigurasi Server Hotspot

Konfigurasi server hotspot masuk pada menu IP - hotspot - server profiles - tanda plus - tab general - berikan nama smk - IP Address - DNS Name di isikan smkn2.id yang nantinya sebagai domain name sistem ketika akan melakukan login hotspot - HTML Directory pilih flash/hotspot yang dimana halaman login sudah termodifikasi dan terletak dalam folder directory tersebut. Tahap pertama membuka menu server hotspot profile terlihat pada Gambar 3.6.

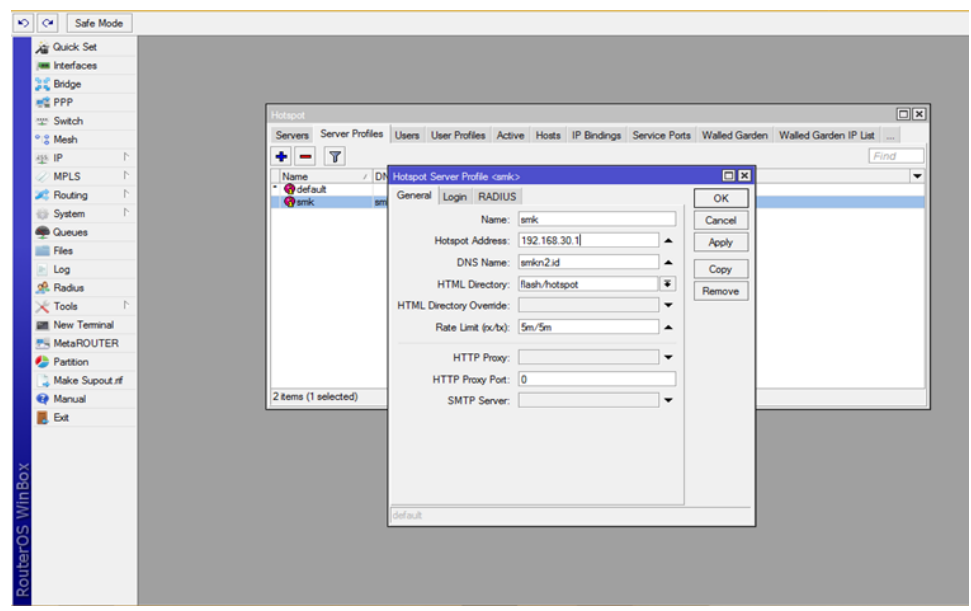

Gambar 3.6. Menu Server Hotspot Profile

2. Melakukan Konfigurasi Load Balancing dan Fail Over

3. Melakukan Konfigurasi Reboot Otomatis

4. Melakukan Konfigurasi Waktu Akses Internet

\subsection{Operate}

Pada tahap ini adalah melakukan pengujian atau mengoperasikan pada sistem yang telah dikonfigurasi yaitu :

1.Menguji Hotspot (user dan staf/guru).

2.Menguji Load Balancing.

3.Menguji Router Reboot Otomatis

Mengecek router apakah berhasil melakukan reboot secara otomatis dengan waktu yang sudah ditentukan menggunakan script code yaitu "/system reboot y" maka router yang telah melakukan reboot dapat terlihat pada list log router dan saat pukul 04.30 WIB router akan melakukan reboot di setiap harinya tentu akan merefresh kinerja dari router. Terlihat pada Gambar 3.7.

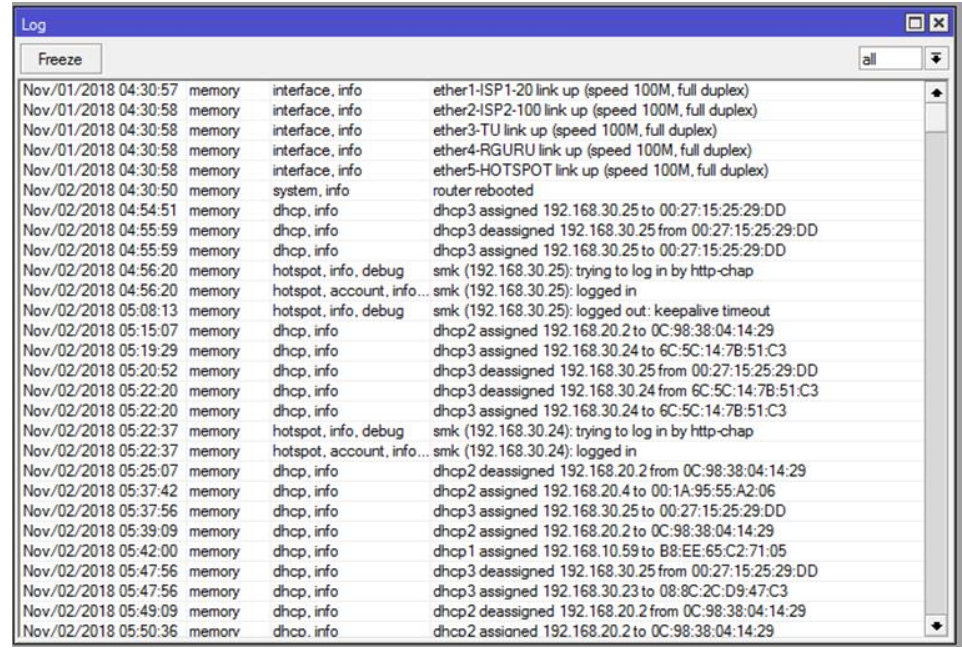

Gambar.3.7 Tampilan router reboot

4.Menguji waktu akses internet 
3.6. Optimize

Tahap ini adalah melakukan perawatan dan pemeliharaan pada jaringan. Untuk memudahkan dalam perawatan dan pemeliharaan maka dibuat berupa penjadwalan yang dimana dapat dilakukan perawatan dan pemeliharaan pada saat diluar hari kerja, sehingga tidak mengganggu pengguna internet. Rencana penjadwalan kegiatan optimize terlihat pada tabel 3.2.

Tabel 3.2. Rencana kegiatan Optimize

\begin{tabular}{|c|c|c|c|c|c|c|c|c|c|c|}
\hline \multirow{3}{*}{$\mathrm{N}$} & \multirow{3}{*}{ Kegiatan } & \multicolumn{9}{|c|}{2018} \\
\hline & & Ostot & & & Note: & $m b x$ & & Dese: & $\sin$ & \\
\hline & & \begin{tabular}{l|l|l|l|}
1 & 2 \\
\end{tabular} & \begin{tabular}{l|l}
3 & 4 \\
\end{tabular} & & 2 & & 4 & 12 & & 4 \\
\hline 1 & Pengecekan Hardware & & & & & & & & & \\
\hline 2 & Rengecekan Software & & & & & & & & & \\
\hline 3 & Pengecekan Konfigurasi & & & & & & & & & \\
\hline 4 & Test Koneksi & & & & & & & & & \\
\hline 5 & Upgrade Sistem & & & & & & & & & \\
\hline 6 & Lain-lain & & & & & & & & & \\
\hline
\end{tabular}

Banyak sekali tools yang digunakan untuk mengecek traffic jaringan atau monitoring traffic dengan melihat setiap akses user bisa menggunakan tool didalam mikrotik seperti yang terlihat pada Gambar 3.8 dimana setiap user dikelompokkan dalam penggunaan bandwidth yang dipakainya.

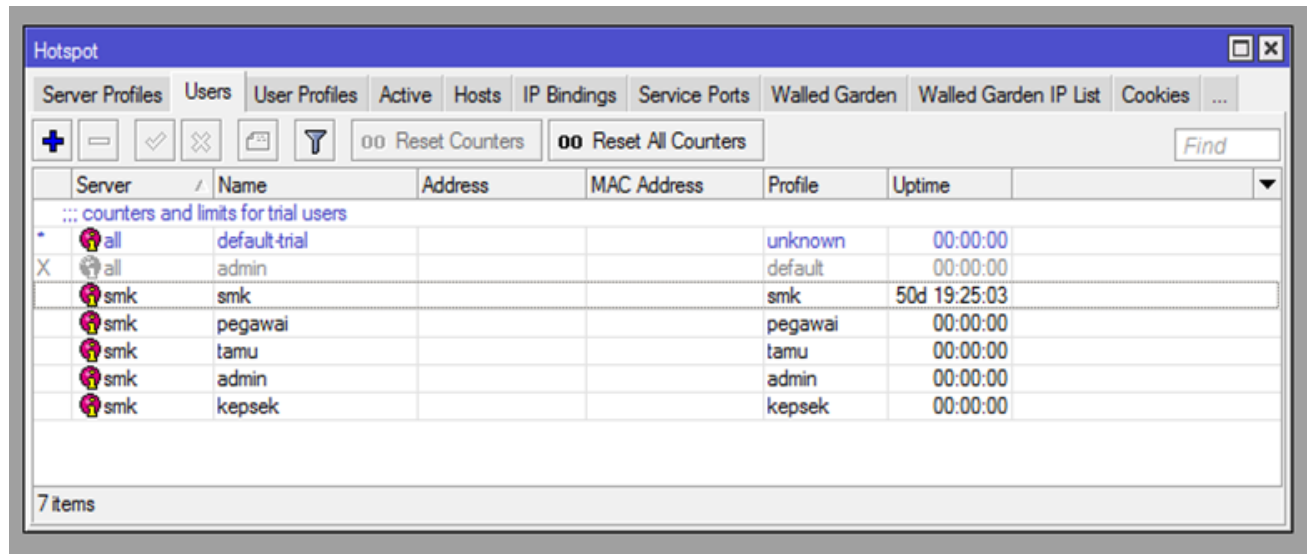

Gambar 3.8 Menu monitoring user

\section{Kesimpulan}

Dengan topologi jaringan internet hotspot yang penulis lakukan dibuktikan bahwa performa wireless LAN meningkat, yaitu :

a. Hotspot login dapat memberikan keamanan, memanagemen bandwidth, user, waktu, dan monitoring traffic.

b. Menggabungkan 2 ISP jika salah satu provider internet terjadi putus koneksi maka provider yang lain akan membackup koneksi sehingga internet akan tetap berjalan.

c. Mengkonfigurasi router untuk melakukan reboot secara otomatis agar dapat merefresh kembali performa dari router sehingga dapat berjalan dengan stabil.

d. Menonaktifkan koneksi jaringan hotspot secara otomatis pada saat diluar jam kerja dan malam hari, bertujuan untuk menghindari pengguna luar yang mencoba akses jaringan hotspot di SMK Negeri 2 Semarang. 


\section{DAFTAR PUSTAKA}

[1] Iwan Sofana. Membangun Jaringan Komputer. Bandung : Informatika . 2013

[2] I Putu Agus Eka Pratama. Handbook Jaringan Komputer Teori dan Praktik Berbasis Open Rource, Bandung : Informatika. 2015

[3] Kustanto. Daniel T, Saputra. Membangun Server Internet Dengan Mikrotik OS. Yogyakarta : Gava Media.2015

[4] Madcom. Membangun Sistem Jaringan Komputer. Yogyakarta : CV.Andi Offset. 2009

[5] Moch. Linto Herlambang, Azis Catur L, Panduan Lengkap Menguasai Router Masa Depan Menggunakan Mikrotik Router OS,Yogjakarta, Penerbit ANDI. 2008

[6] Nugroho Endro. Buku Pintar Jaringan Komputer. Yogyakarta. Modeoms. 2009.

[7] Sukmaaji, Anjik dan Rianto. Jaringan Komputer Konsep dasar Pengembangan Jringan dan Keamanan Jaringan. Yogyakarta : CV. Andi Offset. 2008

[8] Supandi, Dede. Instalasi dan Konfigurasi Jaringan Komputer. Bandung: Informatika.2006 